\title{
DESAIN SISTEM INFORMASI LAYANAN KEUANGAN SEKOLAH BERBASIS CLOUD COMPUTING
}

\author{
Melda Agarina ${ }^{1}$, Sutedi ${ }^{2}$, Arman Suryadi Karim ${ }^{3}$ \\ ${ }^{1}$ Program Studi Sistem Informasi Institut Informatika dan Bisnis Darmajaya \\ ${ }^{2}$ Program Studi Sistem Informasi Institut Informatika dan Bisnis Darmajaya \\ ${ }^{3}$ Program Studi Sistem Informasi Institut Informatika dan Bisnis Darmajaya \\ 1agharina@darmajaya.ac.id \\ ${ }^{2}$ sutedi@darmajaya.ac.id \\ 3armansuryadi@darmajaya.ac.id
}

\begin{abstract}
The financial services system is one that is important in the provision of education in college or also in school. Although education managers' understanding and awareness of the importance of an IT-based financial services system is increasing, there are still many educational institutions that do not yet have the capability to develop and implement IT-based financial services systems due to limited resources and funds. The development of cloud computing-based systems is a new paradigm in the IT world in delivering IT services that enable schools to implement IT-based service systems without having to invest in too large IT equipment. This study discusses the design of system architecture and the development of prototype software supporting school financial services. The results of this study are computer software that can be used to improve school financial services so as to help schools with limited resources and funds in the effort of developing the system
\end{abstract}

Keywords: Financial Service; Cloud Computing; IT Services.

\begin{abstract}
Sistem layanan keuangan merupakan salah satu unsur pendukung penting didalam penyelenggaraan pendidikan di perguruan tinggi maupun juga di sekolah. Meskipun pemahaman dan kesadaran para pengelola pendidikan terhadap pentingnya sistem layanan keuangan berbasis IT semakin meningkat, namun masih banyak institusi pendidikan yang belum memiliki kemampuan untuk mengembangkan dan mengimplementasi sistem layanan keuangan berbasis IT, karena keterbatasan sumber daya dan dana yang dimiliki. Pengembangan sistem berbasis cloud computing merupakan paradigma baru di dunia IT dalam memberikan IT services yang memungkinkan sekolah dapat mengimplementasikan sistem layanan berbasis IT tanpa harus melakukan investasi peralatan IT yang terlalu besar. Penelitian ini membahas mengenai perancangan arsitektur sistem dan pembangunan prototype perangkat lunak pendukung layanan keuangan sekolah. Luaran yang dari hasil penelitian ini adalah berupa perangkat lunak komputer yang dapat digunakan untuk meningkatkan layanan keuangan sekolah sehingga dapat membantu sekolah-sekolah yang memiliki keterbatasan sumber daya dan dana dalam upaya pengembangan sistem tersebut
\end{abstract}

Kata kunci: Layanan Keuangan; Cloud Computing; IT Services.

\section{PENDAHULUAN}

Sistem layanan keuangan merupakan salah satu unsur pendukung penting di dalam penyelenggaraan pendidikan di perguruan tinggi maupun juga di sekolah. Sistem tersebut harus dapat mengorganisir dan mengolah data keuangan secara cepat, mudah, dan akurat. Agar sistem tersebut dapat memiliki kinerja sesuai dengan yang diharapkan, maka sistem tersebut harus dibangun dengan memanfaatkan dan berbasis teknologi informasi (IT).

Meskipun pemahaman dan kesadaran para pengelola pendidikan terhadap pentingnya sistem layanan keuangan berbasis IT semakin meningkat, namun masih banyak institusi pendidikan yang belum memiliki kemampuan untuk mengembangkan dan mengimplementasi sistem layanan keuangan berbasis IT. Alasannya, karena berbagai macam 
kendala yang dihadapi mulai dari kemampuan SDM, keterbatasan dana, serta ketersediaan fasilitas peralatan yang minim. Terkait dengan upaya untuk mengatasi kendala di atas maka diperlukan solusi pengembangan sistem yang dapat meminimasi kebutuhan sumber daya dan dana tanpa mengurangi kinerja dan fitur-fitur yang diharapkan. Saat ini kemajuan IT telah memunculkan berbagai macam konsep, diantaranya konsep pengembangan sistem berbasis cloud computing yang merupakan paradigma baru di dunia IT dalam memberikan IT services. Dengan konsep ini, sekolah dapat mengimplementasikan sistem layanan keuangan berbasis IT tanpa harus melakukan investasi peralatan IT (pengembangan software, pengadaan server, media penyimpanan dan jaringan komputer) yang terlalu besar. Pada penelitian ini dibahas tentang rancangan sistem layanan keuangan sekolah berbasis cloud computing, guna membantu pihak sekolah agar dapat meningkatkan mutu layanan keuangan dengan biaya investasi yang minimalis.

\section{KERANGKA TEORI}

Menurut Tata Sutabri (2005) sistem adalah sekelompok unsur yang erat hubungannya satu dengan yang lain, yang berfungsi bersama-sama untuk mencapai tujuan tertentu. Sedangkan sistem informasi menurut Barry E.Cushing adalah kumpulan dari manusia dan sumber daya modal di dalam suatu organisasi yang bertanggung jawab mengumpulkan dan mengolah data untuk menghasilkan informasi yang berguna untuk semua tingkatan manajemen di dalam kegiatan perencanaan dan pengendalian. (Jogiyanto,2005).

Data yang diolah menjadi informasi biasanya disimpan dalam suatu basis data (database). Menurut Adi Nugroho (2004) basis data didefinisikan sebagai koleksi data-data yang terorganisasi dengan cara sedemikian rupa sehingga data mudah disimpan dan dimanipulasi. Salah satu metode yang sering digunakan dalam pengembangan sistem informasi adalah metode analisis dan desain terstruktur (Structured Analisys and Design / SSAD). Perancangan pada metode ini bertujuan untuk membuat model solusi terhadap problem yang sudah dimodelkan secara lengkap pada tahap analisis terstruktur. Ada empat kegiatan perancangan yang harus dilakukan, yaitu:
a. Perancangan arsitektural.
b. Perancangan data.
c. Perancangan antarmuka.
d. Perancangan procedural.

Salah satu tools yang biasa digunakan untuk membuat model sistem adalah data flow diagram/DFD, simbolsimbolnya disajikan pada Gambar 1.

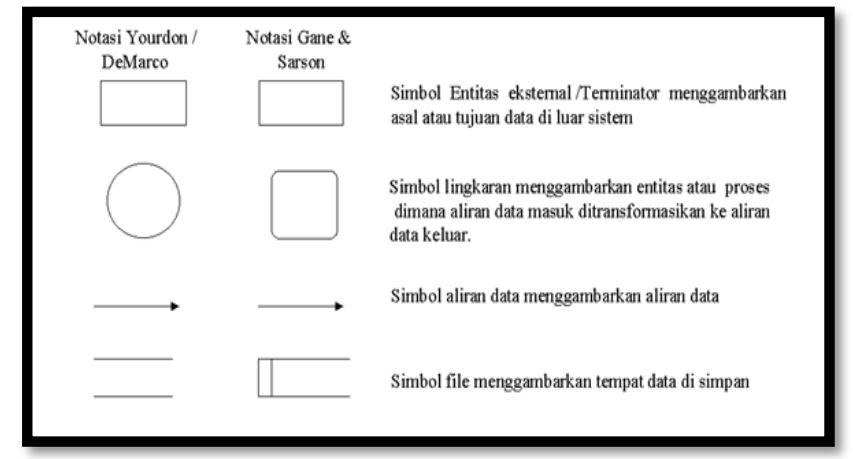

Gambar 1. Simbol-simbol DFD Menurut Adi Nugroho (2004) 
Entity relationship diagram/ERD dan teknik normalisasi adalah tools yang biasa digunakan untuk pemodelan data. (Jogiyanto, 2005). Simbol-simbol ERD dijelaskan pada Gambar 2.

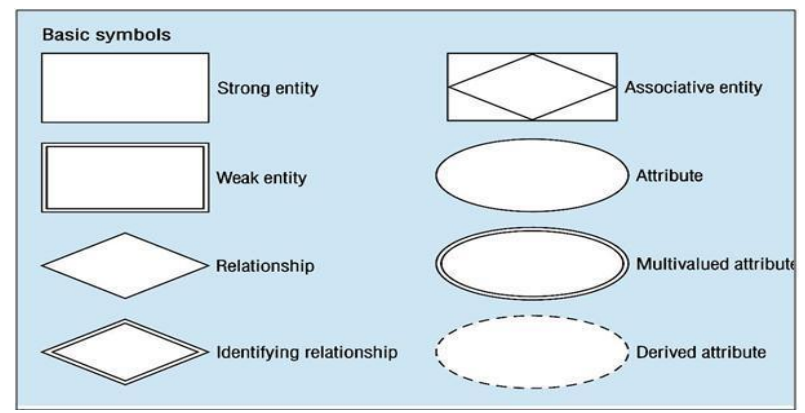

Gambar 2 Simbol-simbol ERD Menurut Adi Nugroho (2004)

Model cloud computing memiliki lima karakteristik utama yaitu On-demand self-service, Broad network access, Resource pooling, Rapid elasticity dan Measured Service (Achmad Solichin dan Zainal A. Hasibuan, 2012)

\section{METODOLOGI}

Guna menunjang penelitian ini, dilakukan proses pengumpulan data dengan metode observasi dan studi literatur. Metode pengembangan sistem yang digunakan dalam penelitian ini adalah metode analisis dan desain sistem terstruktur. Siklus pengembangan sistem dalam metode analisis dan desain sistem terstruktur disajikan pada Gambar 3.

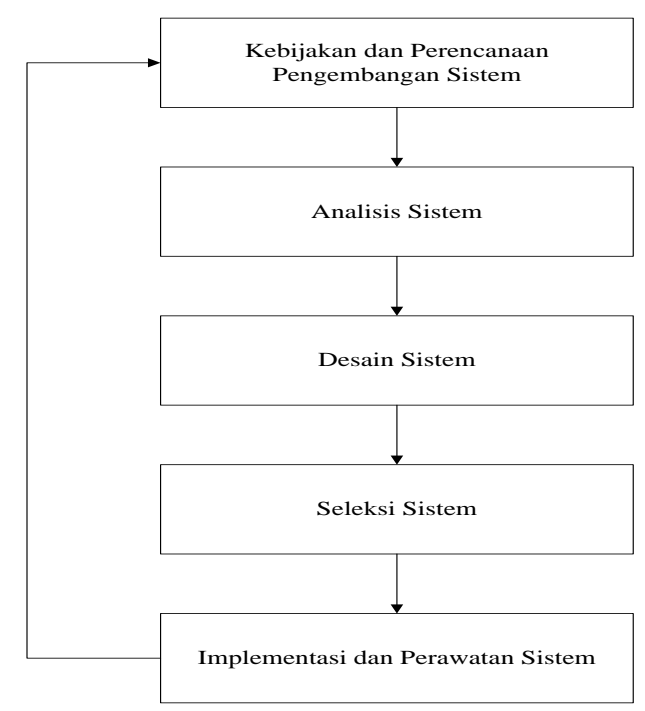

Gambar 3. Siklus Pengembangan Sistem

Pendekatan pengembangan sistem yang digunakan pada penelitian ini, adalah:

a. Pendekatan Terstruktur, dimana proses analisis maupun desain dilakukan tidak hanya mengikuti siklus hidup pengembangan sistem saja melainkan juga dilengkapi dengan alat dan teknik yang memadai untuk mendukung proses yang dilakukan disetiap fase pengembangan sistem.

b. Pendekatan Top-down, dimana pengembangan sistem dilakukan mulai dari perumusan informasi atau keluaran sistem yang akan dihasilkan, kemudian dilakukan pengumpulan data-data pendukungnya.

c. Pendekatan Moduler, dimana pengembangan sistem dilakukan secara bertahap modul per modul sehingga sistem yang kompleks tetap dapat diselesaikan dalam keterbatasan sumber daya yang ada. 


\section{HASIL DAN PEMBAHASAN}

Alur sistem yang berjalan dapat dilihat pada Gambar 4

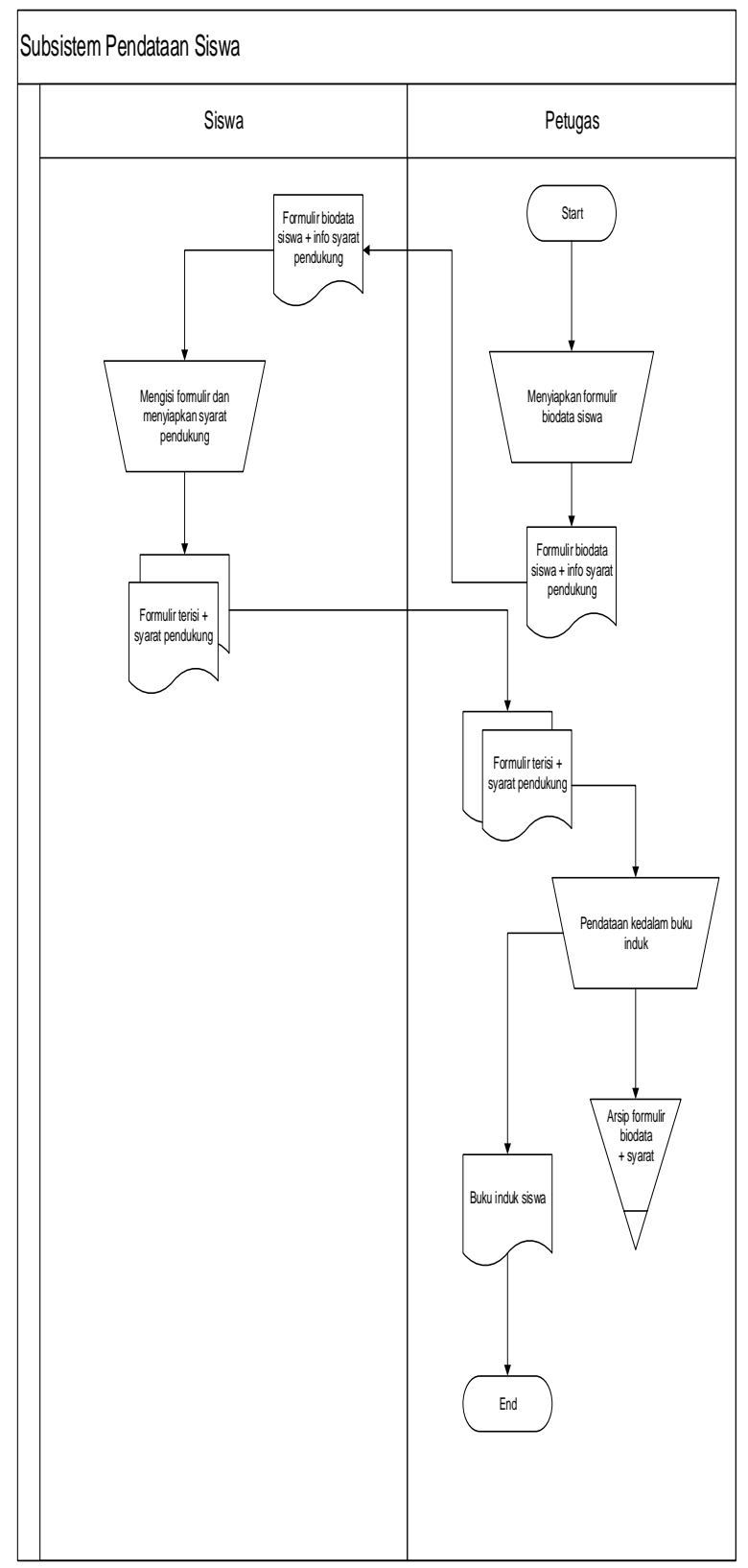

Gambar 4. Sub Sistem Pendataan 


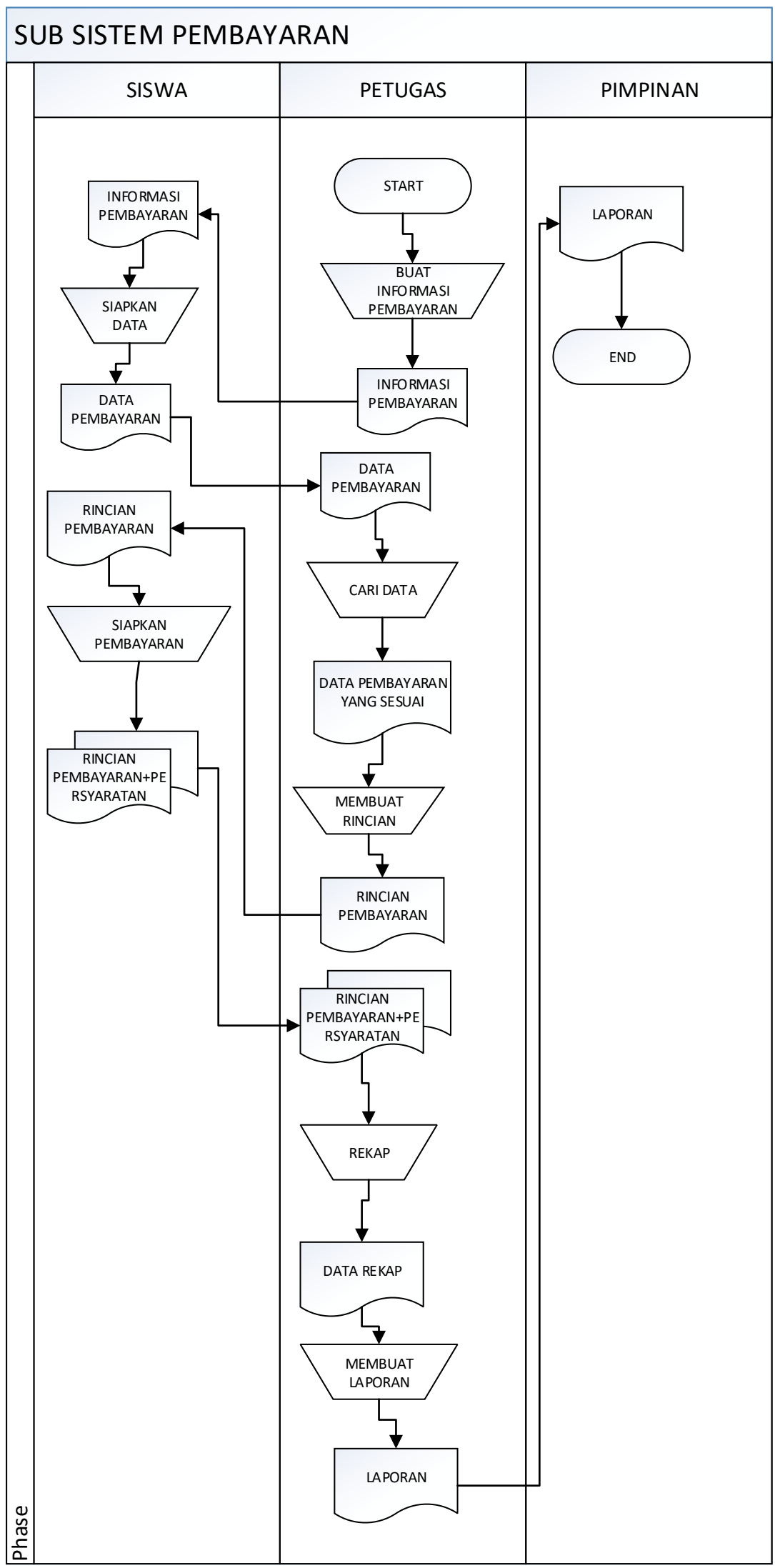

Gambar 5. Sub Sistem Pembayaran 
Dua kelemahan yang dapat diindentifikasi pada ketiga subsistem yang berjalan yaitu:

a. Penyajian, pencarian dan pemutakhiran data siswa tidak dapat dilakukan secara cepat dan mudah karena data siswa diorganisir secara manual didalam buku induk.

b. Penyajian nilai matapelajaran belum dapat dilakukan secara cepat dan mudah.

Sebagai solusi atas permasalahan diatas, diberikan desain model sistem yang diusulkan yang ditunjukkan pada Gambar 6 dan 7.

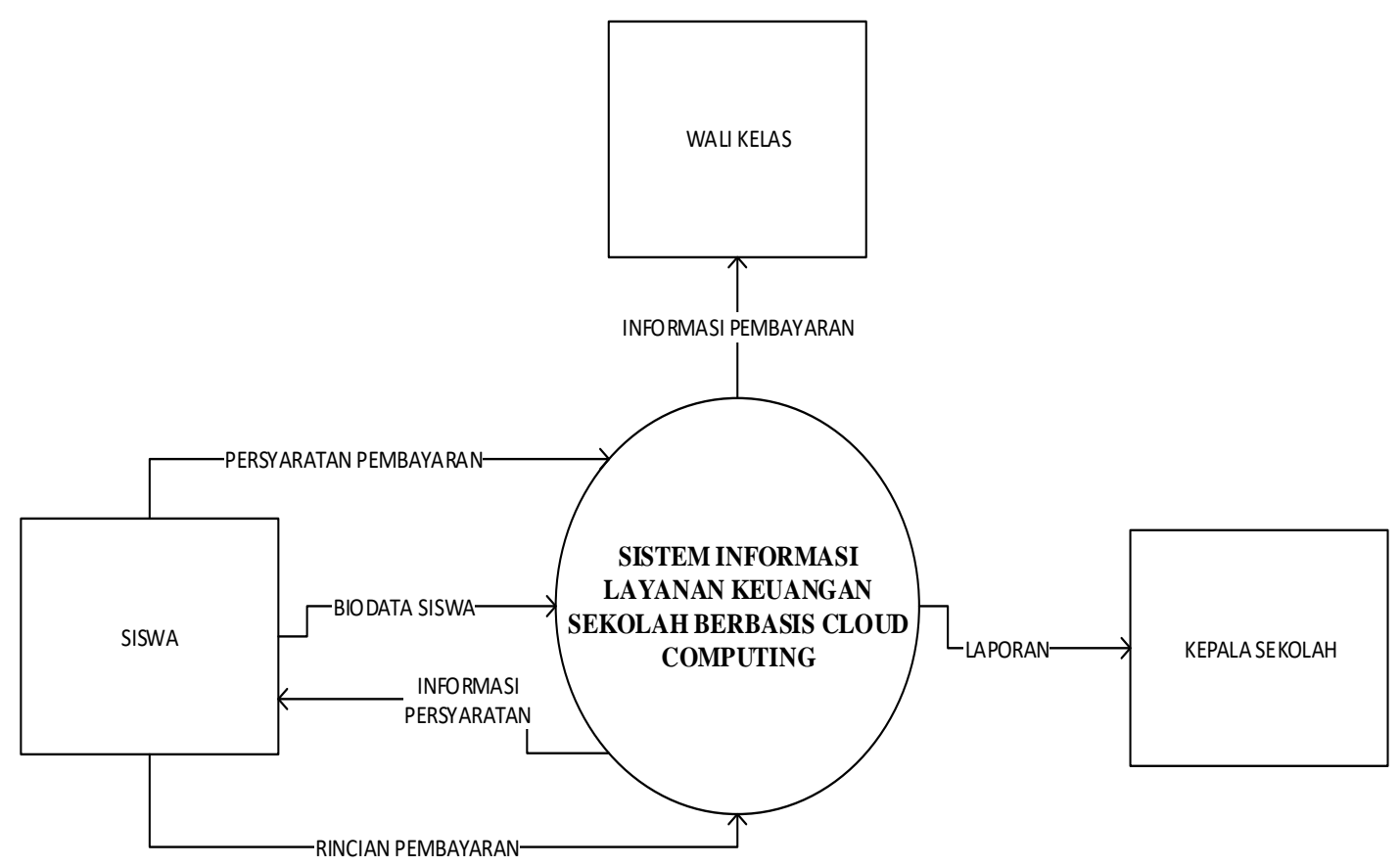

Gambar 6. Context diagram 


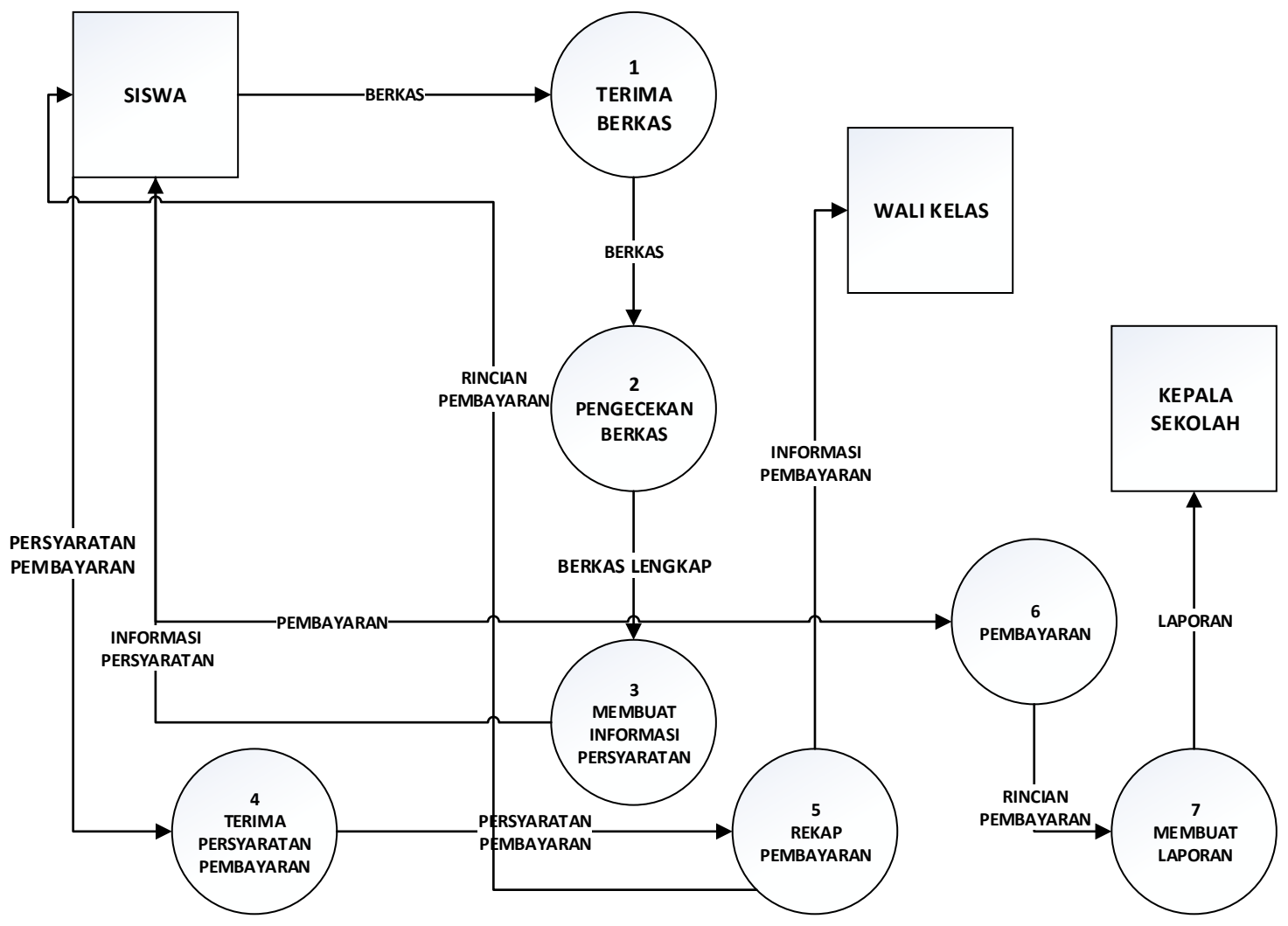

Gambar 7 DFD Level 0

Rancangan form input/output yang diusulkan untuk keperluan sistem yang dikembangkan adalah:

a. Form Pendaftaran Sekolah

Form ini digunakan oleh super admin untuk mendaftarkan sekolah kedalam sistem (Gambar 8).

\begin{tabular}{|c|c|}
\hline $\begin{array}{l}\text { Nomor Statistik Sekolah (NSS) } \\
\text { Nama Sekolah } \\
\text { Tanggal Aktivasi } \\
\text { Password Administrator }\end{array}$ & $\begin{array}{ll}: & \text { FORM PENDAFTARAN SEKOLAH } \\
: & \\
:<<\text { diambil dari sistem > } & \end{array}$ \\
\hline Save & Cancel \\
\hline
\end{tabular}

Gambar 8. Form Pendaftaran Sekolah

b. Form Login

From ini digunakan oleh admin sekolah dan user lainnya untuk masuk kedalam system (Gambar 9).

\begin{tabular}{|lll|}
\hline $\begin{array}{l}\text { NSS } \\
\text { User Name }\end{array}$ & $:$ & FORM LOGIN \\
Password & $:$ & \\
OK & Cadministrator/dll >> & \\
\hline
\end{tabular}




\section{c. Form Pengisian Data Sekolah}

Form ini digunakan oleh admin sekolah untuk memasukkan data sekolah kedalam sistem (Gambar 10).

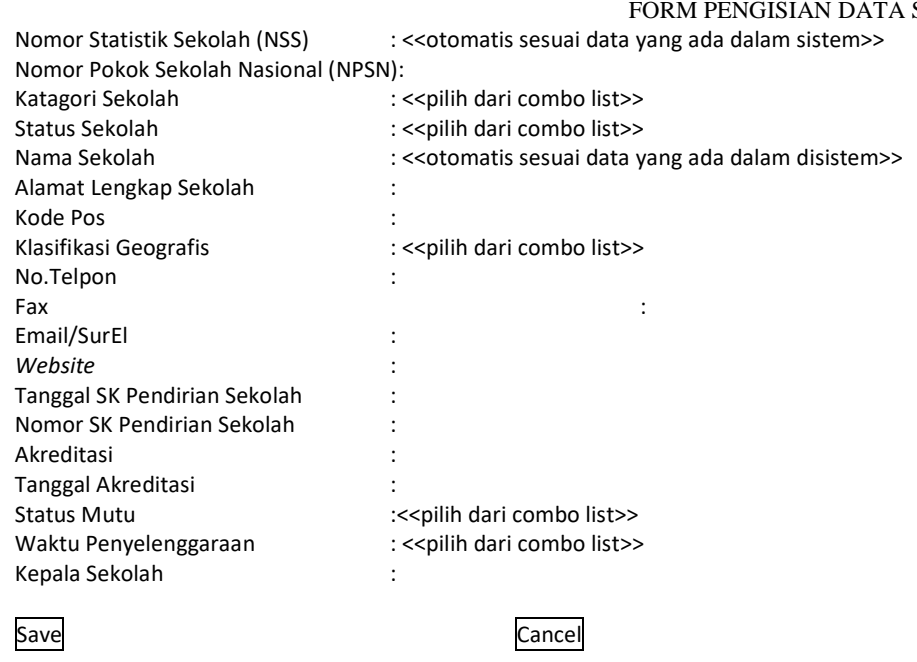

Save Cancel

\section{Gambar 10. Form Penon-aktivan Guru}

\section{d. Form Pengisian Data Pembayaran}

Form ini digunakan oleh admin sekolah untuk memasukkan data pembayaran kedalam sistem (Gambar 11).

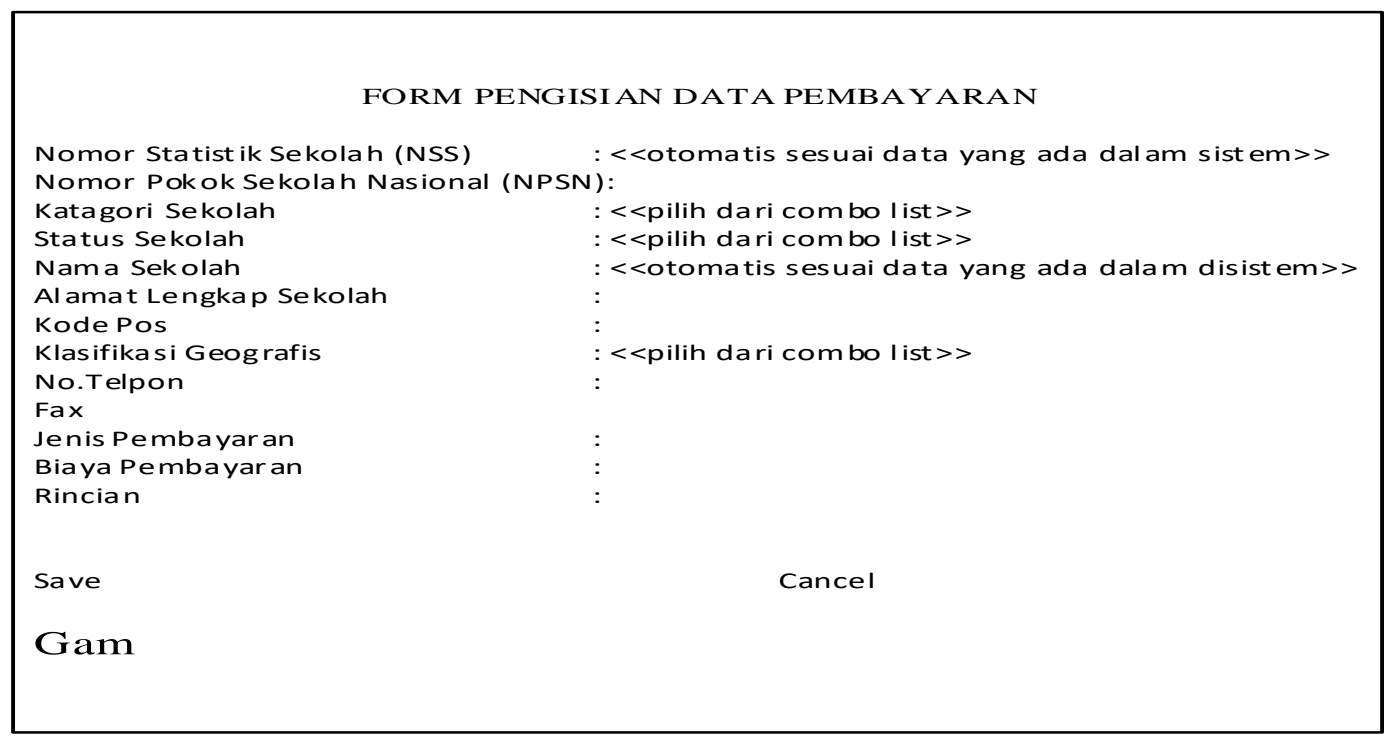

Gambar 11 Form Pengisian Data Pembayaran

Berdasarkan form input/output yang telah didesain, selanjutnya dilakukan desain database yang diperlukan untuk menampung data dan menghasilkan data yang diperlukan. Desain tersebut dapat dilihat pada Gambar 12. dalam bentuk diagram relasi antar tabel. 


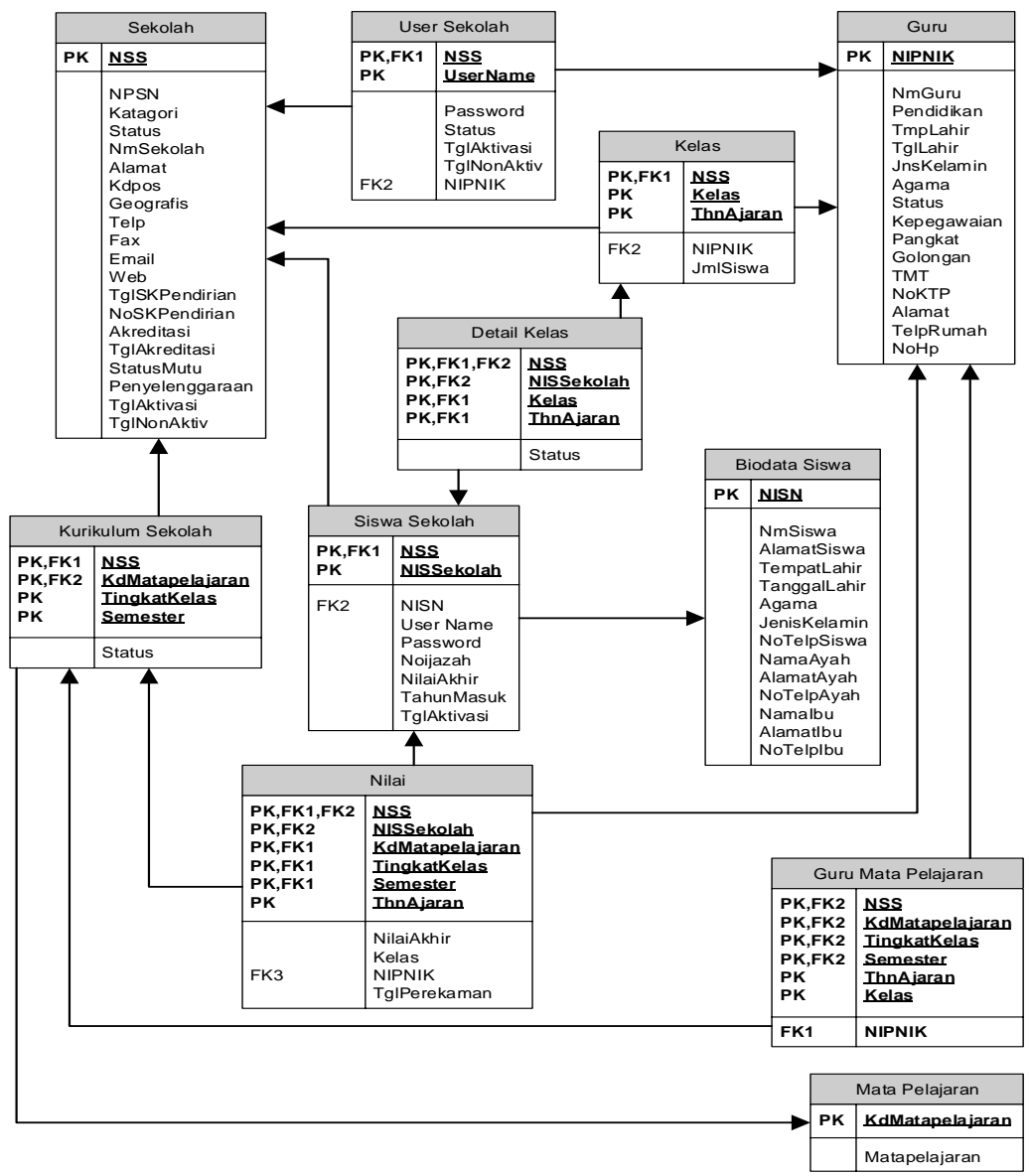

Gambar 12. Diagram Relasi Antar Tabel

Prototype aplikasi yang telah dibangun dapat diakses diinternet dengan alamat Siakadbersama.com. Berikut adalah struktur menu program aplikasi yang diusulkan pada prototype sistem layanan keuangan sekolah berbasis cloud computing disajikan pada Gambar 13.

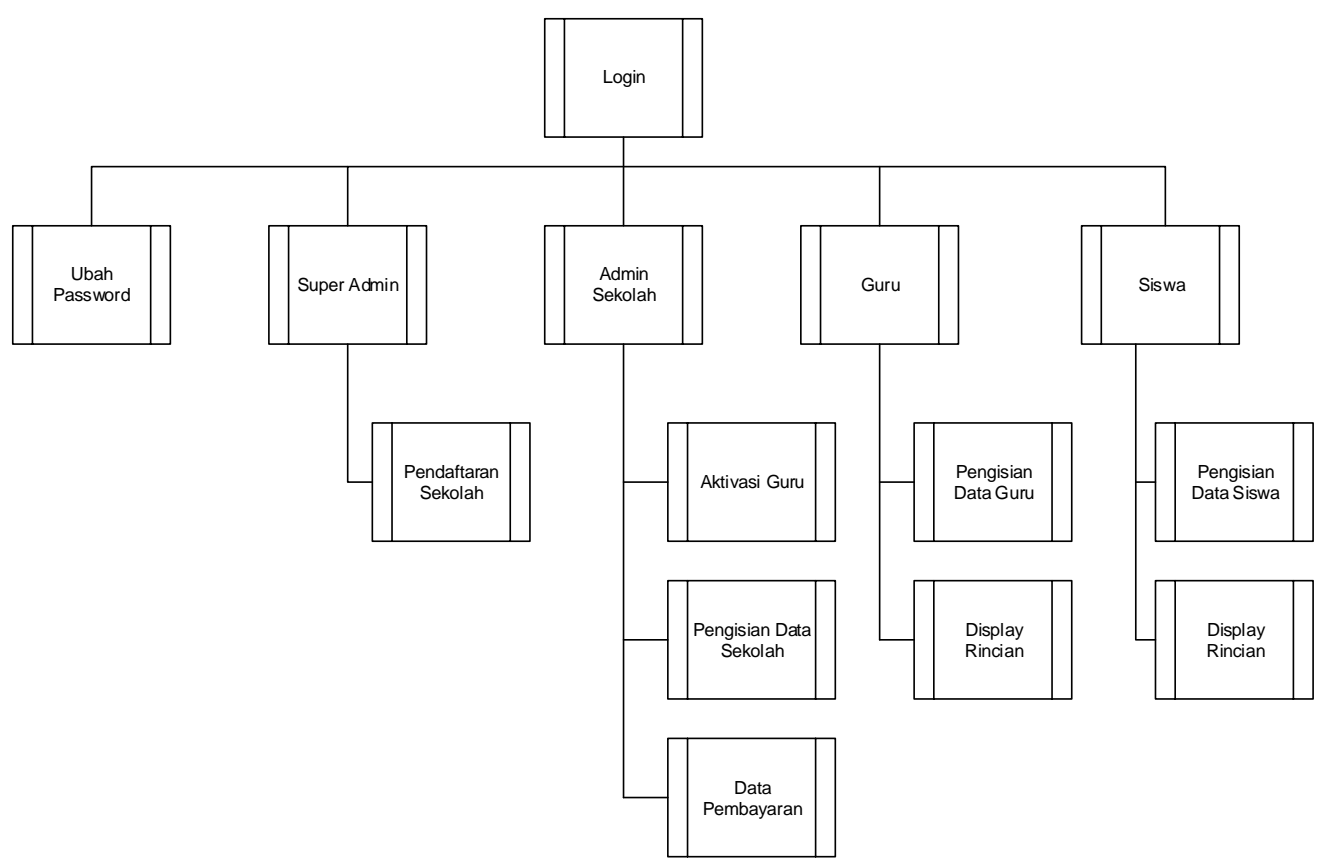

Gambar 13 Struktur Menu Aplikasi 


\section{KESIMPULAN}

Berdasarkan pembahasan yang telah dilakukan sampai dengan tahap ini, maka dapat ditarik beberapa kesimpulan berikut.

a. Aplikasi berbasis cloud computing menuntut desain database yang dapat berbagi data tanpa melanggar hak dan kewenangan masing-masing penggunanya

b. Aplikasi yang dibangun harus dapat melakukan pembagian hak akses secara baik dan menjamin keamanan data penggunanya.

\section{DAFTAR PUSTAKA}

Hartono, Jogiyanto. 2005. Analisis \& Desain Sistem Informasi: Pendekatan Terstruktur Teori dan Praktek Aplikasi Bisnis, Yogyakarta, Penerbit Andi.

Nugroho, Adi. 2004. Konsep Pengembangan Sistem Basis Data, Bandung, Informatika

Sutabri, Tata. 2005. Analisis Sistem Informasi, Yogyakarta, Penerbit Andi.

Solichin, Achmad dan Hasibuan, Zainal A. 2012. Pemodelan Arsitektur Teknologi Informasi Berbasis Cloud Computing Untuk Institusi Perguruan Tinggi di Indonesia. Jakarta PT. Elex Media Komputindo. 